\title{
METHODOLOGY DEVELOPMENT FOR DESIGN AUTOMATION AND OPTIMIZATION OF AN AUTOMOTIVE CRASHBOX
}

\author{
Mariana Rollo Batista, Alysson Lucas Vieira, Matias Meroniuc \\ Smarttech Tecnologia \\ mariana.batista@smarttech.com.br, alysson.vieira@smarttech.com.br, \\ matias.meroniuc@smarttech.com.br
}

\begin{abstract}
With the decrease in purchasing power by consumers, resulting in lower sales, coupled with fierce competition, companies increasingly need to improve their products to stay competitive. One of the segments that suffer most from the fall in consumption is the auto industry, which also faces a more demanding consumer with the quality and safety of the products offered. When it comes to safety, there are still government requirements that the automotive industry needs to reach, thereby, thus it becomes indispensable the search for greater productivity like projects automation and products optimization, one of these products is a set of folded and welded plates, called crashbox, where the front bumper is assembly on it and it has the important function of absorbing the maximum energy due to the frontal vehicle impact, reducing the energy amount that reaches on the vehicle occupants, thus, the aim of this work is to present an automating methodology for the crashbox design with consequent optimization, getting an more efficient and lightness product as possible, thus generating a cost reduction in the product final value.
\end{abstract}

\section{INTRODUCTION}

The automotive industries has large sectors dedicated to the numerical simulation by finite elements, where the clear intention is the reduction of physical prototypes, reducing the cost and the time of projects, in addition to this there is the increasing increase of analyzes that take into account the product optimization that has often been correctly designed that is achieving the project performance objectives, but that it may suffer some reduction, either in the cost of the final part or its manufacturing process, continuing within the specified objectives for the same, thereby improving the competitiveness of enterprises.

The vehicle safety area does not escape this rule, since, in most cases, it requires the construction of a complete vehicle prototype, which raises the cost and construction time, so the gain with simulations is quite significant And each component that can be simulated and optimized in virtual form becomes a big gain, because with the simulation being executed correctly, the expensive prototypes used for impacts are diminished. 
One of the tests that is gaining importance in the Brazilian scenario is the frontal impact of a vehicle against a rigid barrier, where it must meet several requirements, among them, the greater absorption of energy by the structure of the vehicle with the consequence that this energy generated by the impact and one of the structures of this set, which acts in the absorption of this energy is called a crashbox, so the optimization of a crashbox, in the initial stage of its design, is an excellent way to build a Part that meets the energy absorption requirements and still produces a cost reduction of the final part.

\section{GENERAL INFORMATIONS}

According to the European impact standard, ECE 94, the vehicle must meet a fixed barrier at a speed of $56 \mathrm{~km} / \mathrm{h}$ [1]. This impact generates a lot of energy, which is transferred to the vehicle.

For absorption of this energy or in case of accidents, the main source of energy absorption are the parts mounted on the front of the vehicle, which helps protect the passenger compartment and the occupants themselves [2].

One of the energy absorbers is the crashbox, which is also used to control the deceleration pulse of the vehicle during impact and dissipates the impact kinetic energy through its plastic deformation [3]

Figure 1 shows an image with a crashbox positioning example on the vehicle front

Figure 1: Crashbox positioning [4]

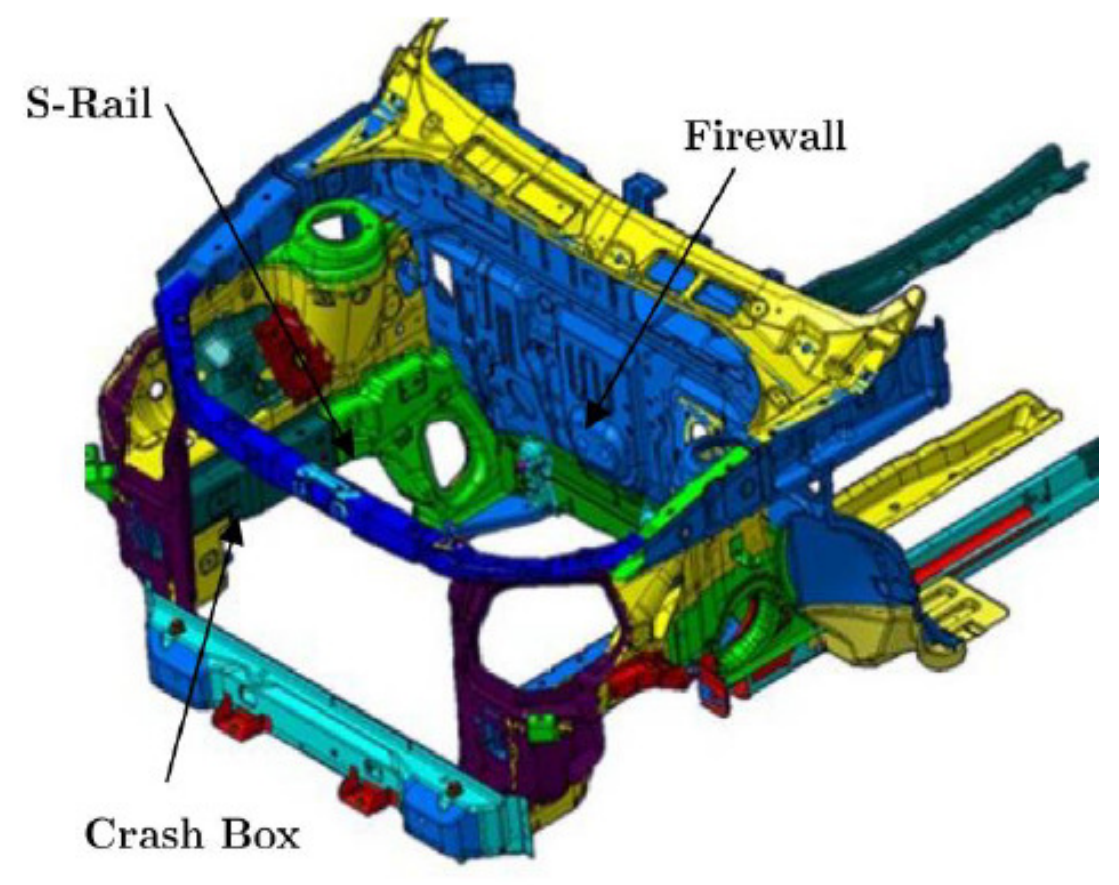


The crashbox has a high energy absorption capacity so it plays an important role in vehicle development accidents [5], making it possible to optimize it, a task of great relevance during the project.

Several optimization methods have been developed, since the optimization aims to obtain better results in certain circumstances, in order to minimize efforts and maximize the desired benefit, and to that end, there is no single means available to solve the problems [6].

In general, the optimization has a very wide flexibility, since it is possible to improve the project by changing several variables depending on the final project objective [7]. For greater project efficiency gain, some optimization types can be used, which can be defined according to objective. Basically, the optimization can be divided into three groups, parametric, shape and topology optimization [8].

- Topology optimization: It is more generic than optimization form, since it allows a more pronounced distribution of material in the domain of the project domain and the inclusion of new "holes" in the domain [8].

- Parametric optimization: It is sought to obtain the mass distribution in a defined element. A typical problem is the ideal distribution of the thickness of a linearly elastic plate or ideal member area of a truss structure. This ideal thickness distribution can minimize or maximize physical model quantities, peak stresses, deflections, etc. While balance and other constraints on the state and project variables are realized [9].

- Form Optimization: Where the segments contour shape and the holes position are modified. In form optimization the goal is to find the optimal form of the domain, that is, the form problem is defined in a domain that is now the design variable [9].

The model studied in the present study used form and parametric optimizations, as can be observed in the methodology.

\section{METHODOLOGY}

For the proposal execution of create a crashbox optimization methodology, a numerical model (model named "v0") with geometry equal to that of the physical part was first evaluated to verify the correct correlation of the proposed mathematical model with the physical model.

The test consists of a mass of 1.6 Ton making an impact on the crashbox, falling from different heights $(100,400$ and $900 \mathrm{~mm})$, for the numerical analysis by finite elements, commercial software Abaqus ${ }^{\circledR}$ version 2017 was used. Figure 2 presents the numerical model boundary conditions. 
Figure 2: Original model ("v0"), boundary conditions.

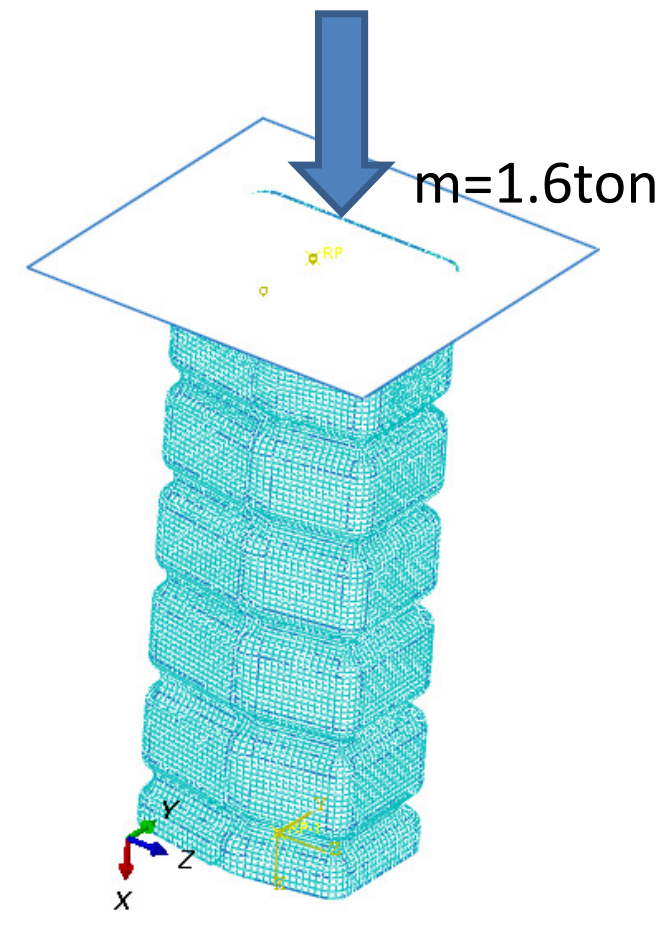

\section{Constrained base}

After the model $v 0$ correlation with the physical test, an alternative geometry (called "v1") with $50 \mathrm{~mm}$ smaller than the studied piece, v0 model, was proposed, and this model will be optimized to maintain the same $v 0$ model dissipated deformation internal energy response, with the function of this model being more economical regarding the material and minimizing the vertical deformation (displacement). A comparison between the two geometries is presented in Figure 3.

Figure 3: Visual comparison between models. A) Original Model v0. B) Proposed model v1
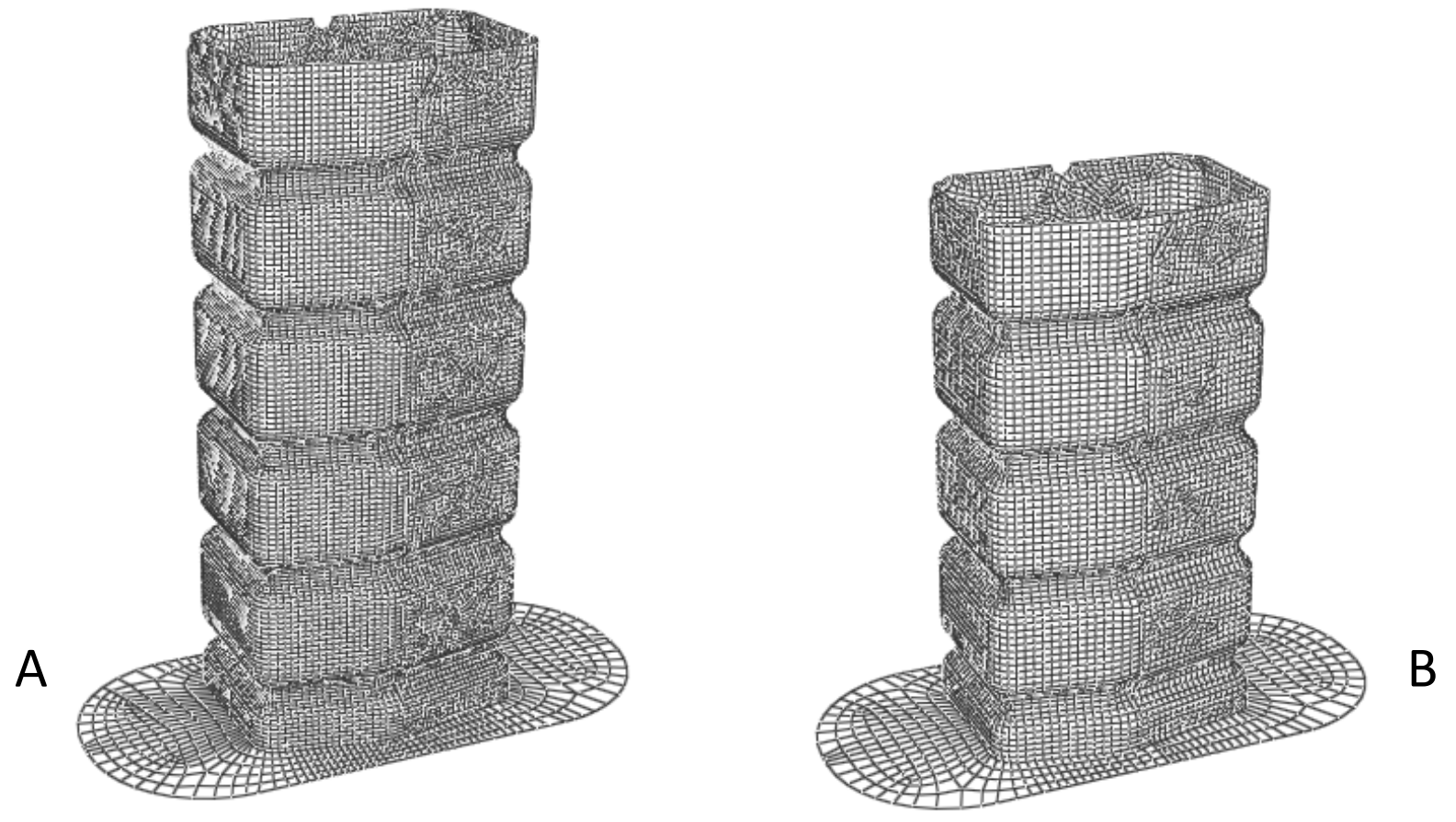
In order to obtain the desired results for crashbox v1, that is, an optimized part, the commercial software Isight ${ }^{\circledR}$ version 2017 was used, where an optimization flow can be set with the material, thickness and shape variables of the part, the software Isight $^{\circledR}$ allows communication between different programs that will have different functions and thus, each program will be responsible for a part optimizatio, that is, the variables are modified and an analysis is launched to verify how effective this modification was. Figure 4 shows the flow used.

Figure 4: Isight ${ }^{\circledR}$ Flow.

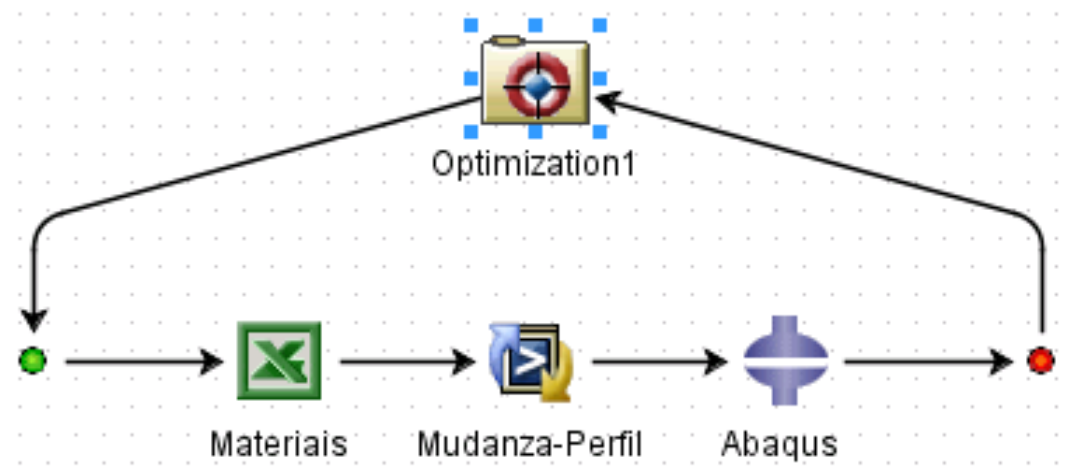

The material and the thickness of the crashbox are inserted into the flow through an Excel worksheet, the Isight ${ }^{\circledR}$ flow first component, material values and thickness can be observed in Figure 5.

Figure 5: Excel worksheet.

\begin{tabular}{|c|c|c|c|}
\hline D & $E$ & $\mathrm{~F}$ & $\mathrm{G}$ \\
\hline $10 \mathrm{~S}$ & $\rightarrow \quad 1$ & 2 & \\
\hline $\mathrm{E}[\mathrm{MPa}]$ & 210000 & 190000 & \\
\hline Módula Young & 0,3 & 0,29 & \\
\hline$\rho\left[\text { Ton } / \mathrm{mm}^{\wedge} 3\right]^{*} 100$ & $7,80 \mathrm{E}-09$ & $7,60 \mathrm{E}-09$ & \\
\hline бbr [MPa] & 900 & 1200 & \\
\hline opl & $\varepsilon \mathrm{pl}$ & $\sigma p l$ & spl \\
\hline 437,22 & 0 & 524,664 & 0 \\
\hline 449,4 & 0,0187 & 539,28 & 0,0187 \\
\hline 495,57 & 0,028 & 594,684 & 0,028 \\
\hline 597,82 & 0,059 & 717,384 & 0,059 \\
\hline 699,85 & 0,1245 & 839,82 & 0,1245 \\
\hline 795,95 & 0,297 & 955,14 & 0,297 \\
\hline 860,98 & 0,5756 & 1033,176 & 0,5756 \\
\hline 1148 & 1,9942 & 1377,6 & 1,9942 \\
\hline Espessura & 1,6 & 1,6 & \\
\hline Material & 2 & & \\
\hline Dados Analise & & & \\
\hline $\mathrm{E}[\mathrm{MPa}]$ & 190000 & & \\
\hline Módulo Young & 0,29 & & \\
\hline$\rho\left[\text { Ton } / \mathrm{mm}^{\wedge} 3\right]^{*} 100$ & $7,6 \mathrm{E}-09$ & & \\
\hline obr [MPa] & 1200 & & \\
\hline opl & $\varepsilon p l$ & & \\
\hline 524,664 & 0 & & \\
\hline
\end{tabular}


The elastoplastic properties for two materials identified with two IDs: 1 and 2 are shown. Then, each of them will be called to the flow with a conditional relation as a function of the presence of the value 1 or 2 (cell in orange). The thickness is directly read from the cell in yellow.

The shape of the set is modified in the commercial pre-processing software ANSA ${ }^{\circledR}$ version 16, which is the second component of the Isight ${ }^{\circ}$ flow called "MudanzaPerfil", it modifies the column cross-section by changing its width and length. Figure 6 shows the limits imposed for the cross section change.

Figure 6: Modification of the model using ANSA ${ }^{\circledR}$ software.

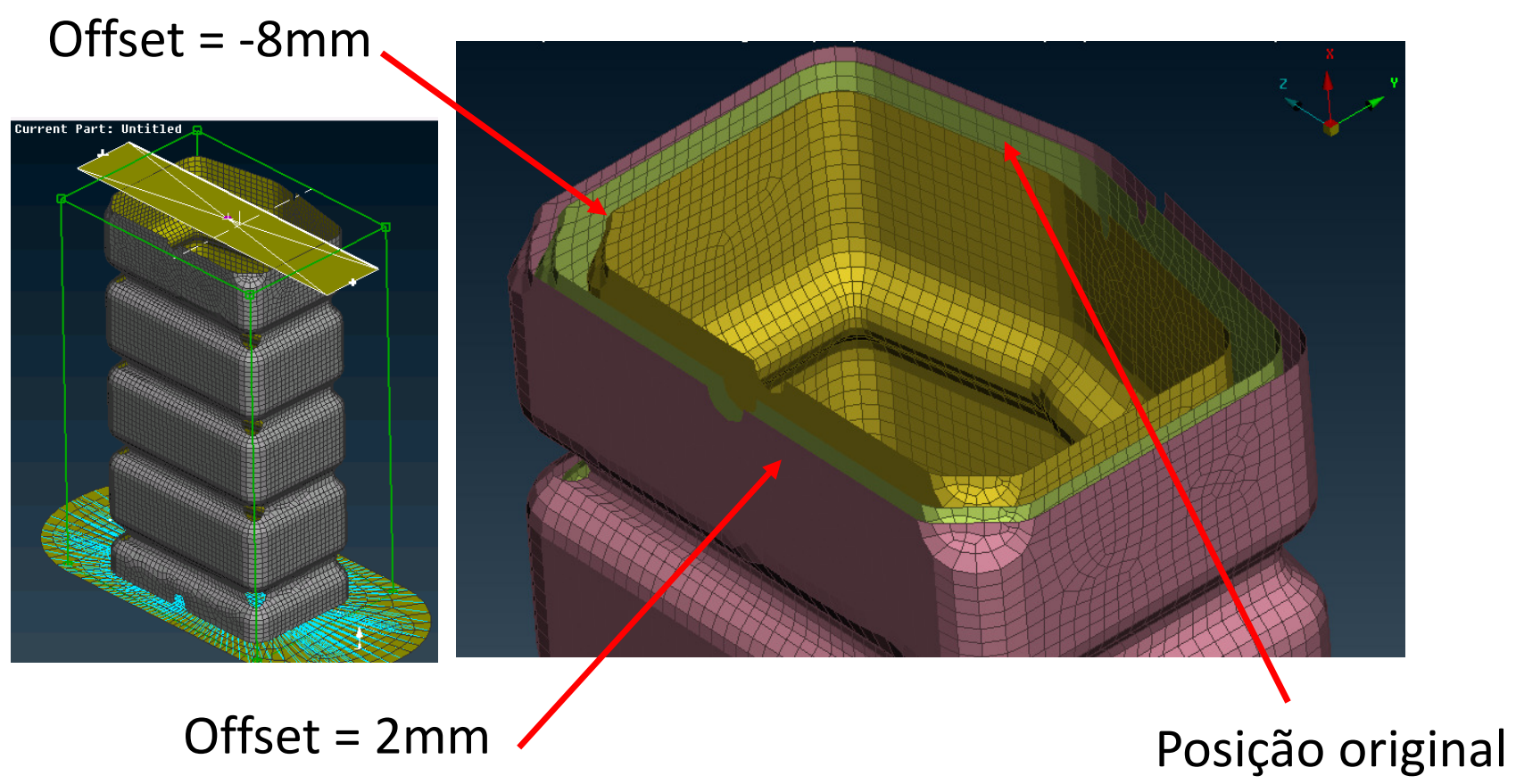

The Abaqus ${ }^{\circledR}$ component purpose is to be used as a solver, that is, to run the input crashbox $v 1$ file hat is modified based on the information provided by the previous components, Excel and ANSA $®$. The analysis consists of the16-ton piece drop at an impact velocity of $100 \mathrm{~mm} / \mathrm{s}$ on crashbox. Figure 7 shows the chart parameters that are subject to Abaqus ${ }^{\circledR}$ component modifications. 
Figure 7: Abaqus ${ }^{\circledR}$ component, input variables.

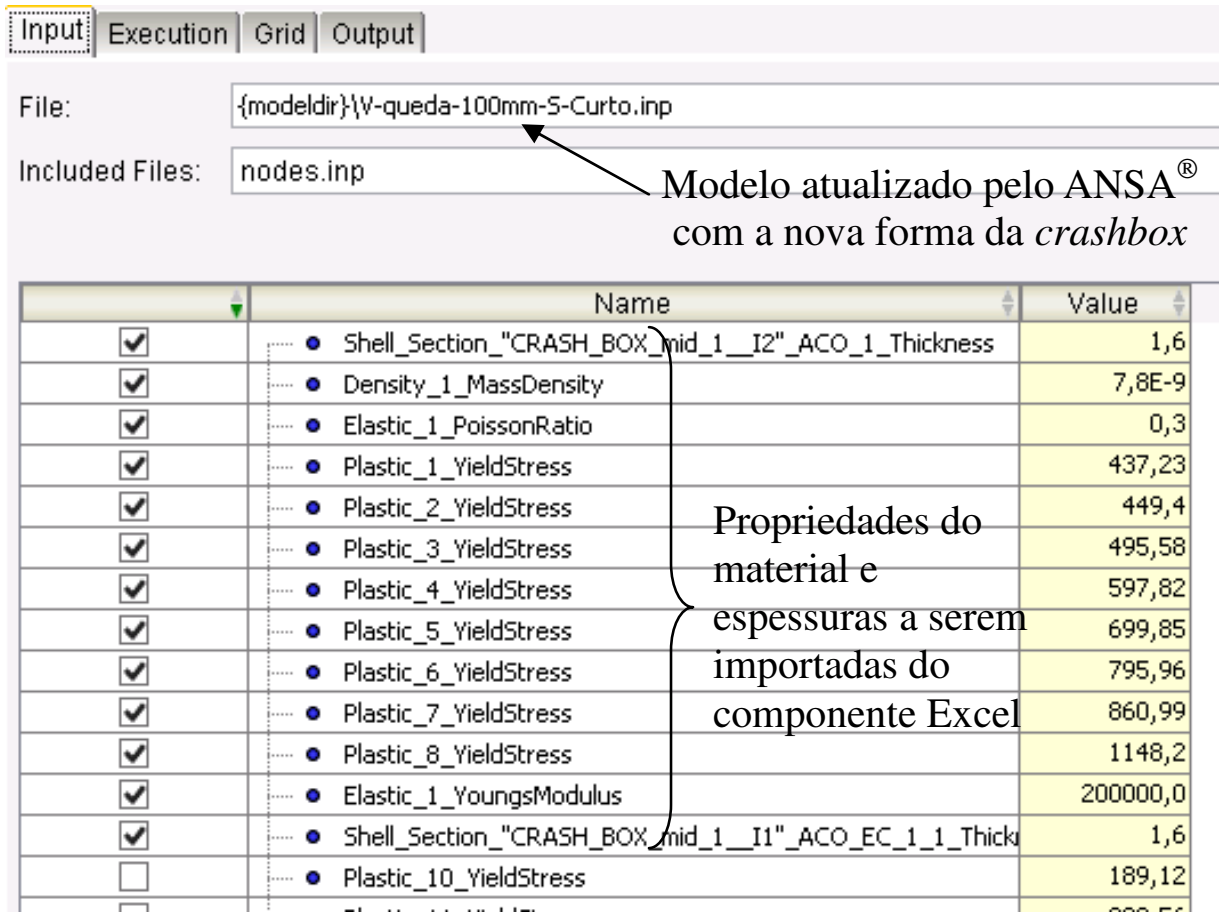

The Abaqus ${ }^{\circledR}$ component will also allow selection of the simulation output information to be used by the optimization algorithm to evaluate the model behavior, which are the internal energy dissipated, vertical penetration of the mass on the column and the mass minimization, as shown in figure 8.

Figure 8: Abaqus $^{\circledR}$ component, output variables used to evaluate the model.

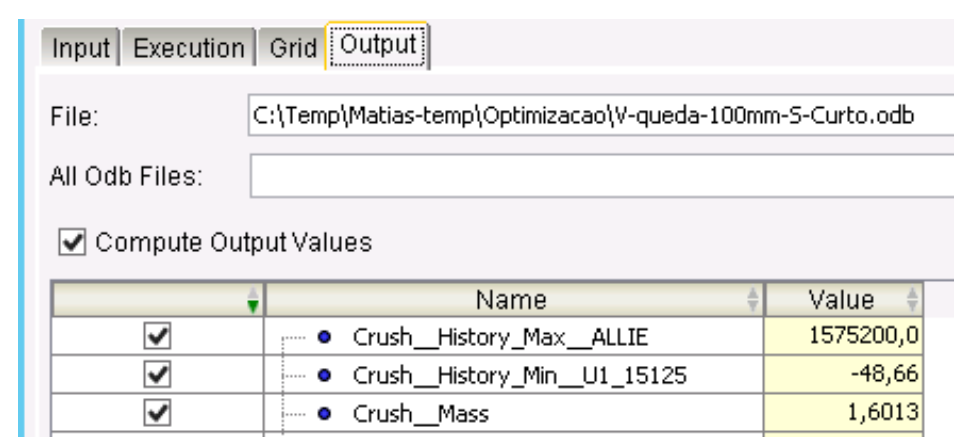

Finally, it is necessary to configure the "Optimization1" component that will command the optimization algorithm determining the input variables variation for the different loops as a function of the model response.

As mentioned previously, the inputs that will be modified are the thickness, the material and the offset to be applied to the mesh. Figure 9 shows the Optimization component variables. 
Figure 9: Input variables for the optimization algorithm.

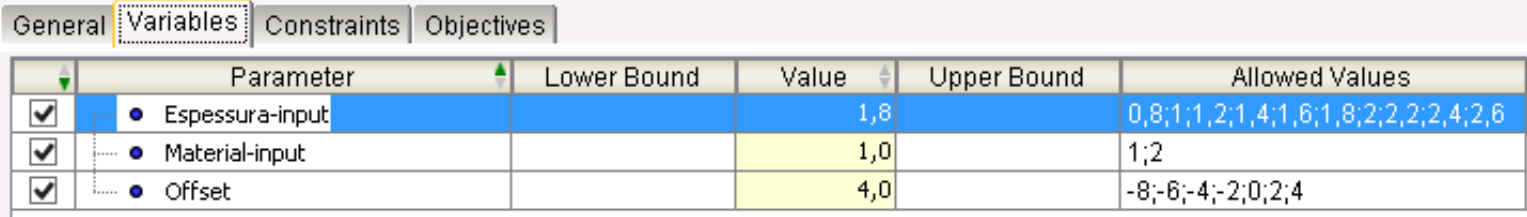

As restrictions, a $1578400 \mathrm{~mJ}$ minimum energy dissipation was adopted, since this was the energy dissipated in the model v0 correlated with the practice, as well as the minimization of mass and the penetration of the mass in vertical drop, can be observed in the figure 10 the energy constraint in the Optimization component.

Figure 10: Model constrain.

\begin{tabular}{|c|c|c|c|c|c|}
\hline \multicolumn{2}{|c|}{ General } & Variables & Constraints & Objectives & \\
\hline 7 & \multicolumn{4}{|c|}{ Parameter } & Lower Bound \\
\hline$\nabla$ & & - Crush_ & History_Max_ & ALLIE & 1578400,0 \\
\hline$\square$ & $\ldots$ & - Crush_ & _History_Min__L & U1_15125 & \\
\hline
\end{tabular}

With this, it is intended to achieve a smaller cross section so that it is light and with the lowest penetration possible.

\section{RESULTS}

The present chapter intends to present the results found and the comparative of the virtual model with physical and virtual with virtual models.

For the original model "v0", after the drop analyzes of a 16 ton mass at 100, 400 and $900 \mathrm{~mm}$ distances, the following results were obtained compared with the tests on the real body, shown in figure 11. 
Figure 11: Comparative results between the v0 model and the physical test part.

a)100 mm drop. b)400 mm drop. c) $900 \mathrm{~mm}$ drop
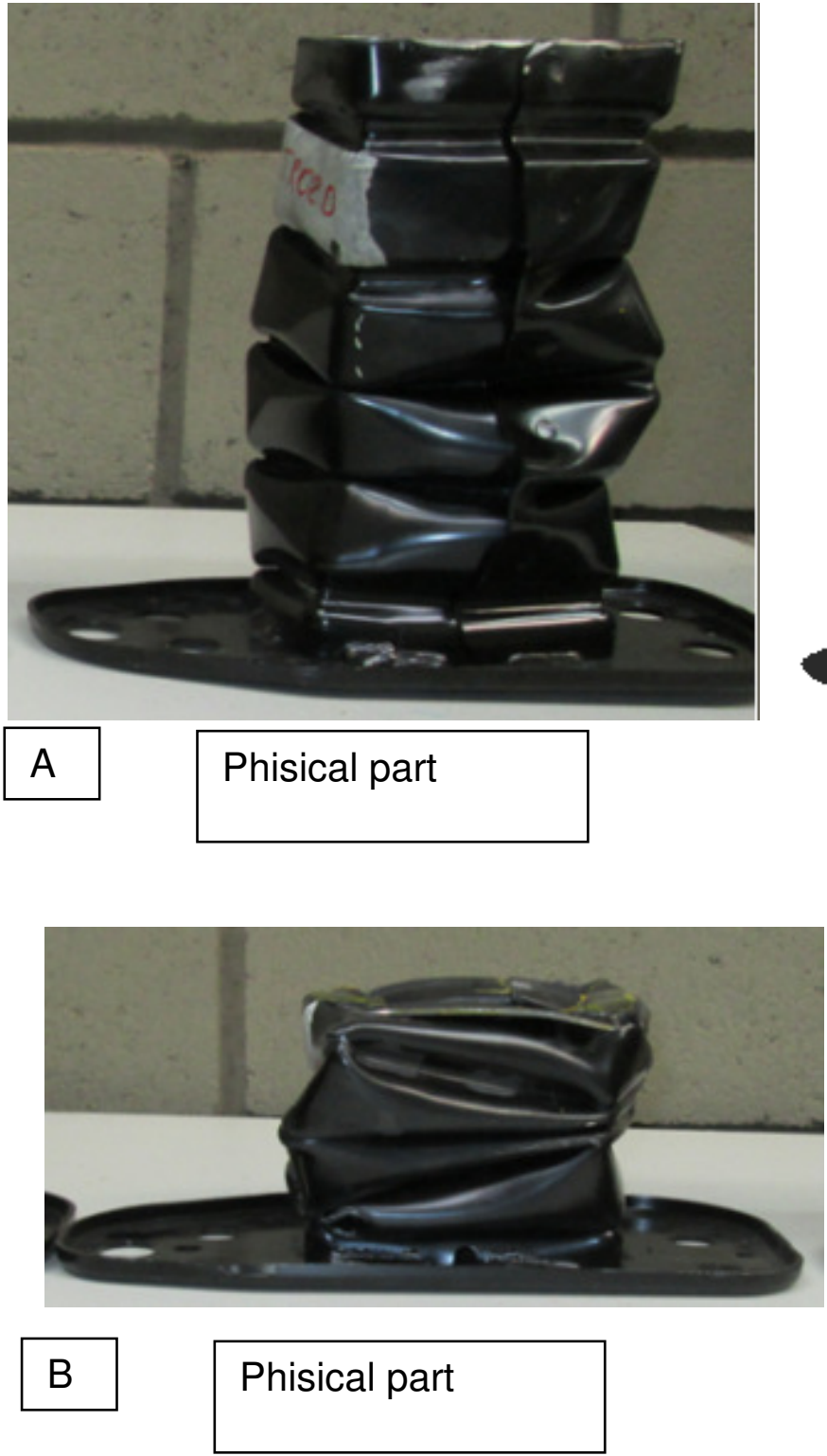

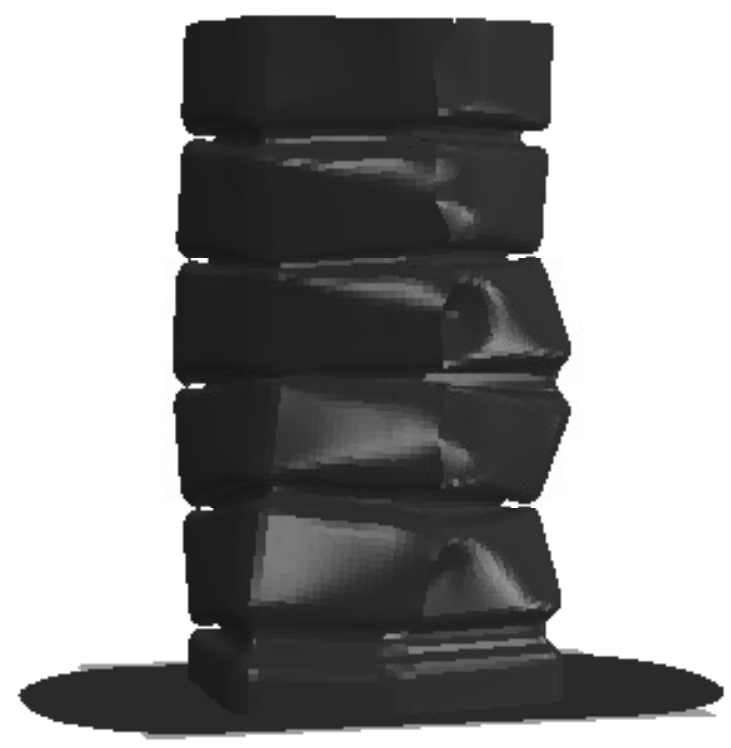

Virtual model v0

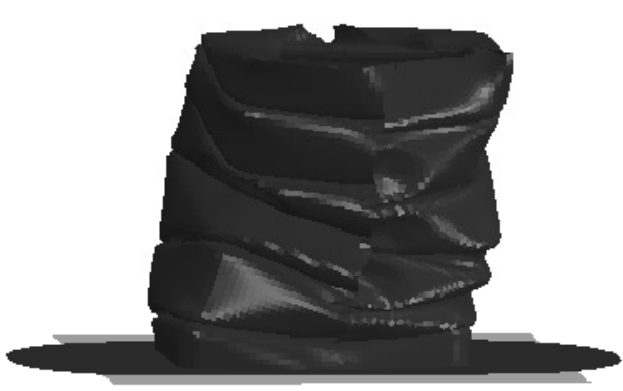

Virtual model v0

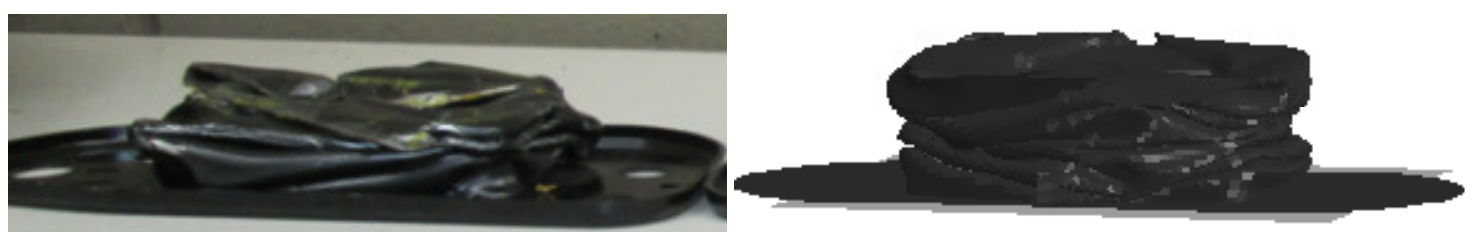

C Phisical part

Virtual model v0 
Table 1 presents the deformations comparative results at the height of the physical and virtual models for each test.

Table. 1: Comparative test results.

\begin{tabular}{|cccc|}
\hline Drop Test & $\begin{array}{c}\Delta \text { h Phisical } \\
\text { Model }\end{array}$ & $\begin{array}{c}\Delta \text { h Virtual } \\
\text { Model }\end{array}$ & \% Difference \\
\hline $100 \mathrm{~mm}$ & $48 \mathrm{~mm}$ & $50 \mathrm{~mm}$ & 4.1 \\
\hline $400 \mathrm{~mm}$ & $159 \mathrm{~mm}$ & $147 \mathrm{~mm}$ & 8.1 \\
\hline $900 \mathrm{~mm}$ & $225 \mathrm{~mm}$ & $225 \mathrm{~mm}$ & 0 \\
\hline
\end{tabular}

With the drop correlation reaching reliable values for the virtual model, we verified the energy dissipated in the virtual model to be taken as the basis for the v1 model. Figure 12 shows the graph of dissipation by mass drop.

Figure 12: Internal energy (ALLIE) for "v0".

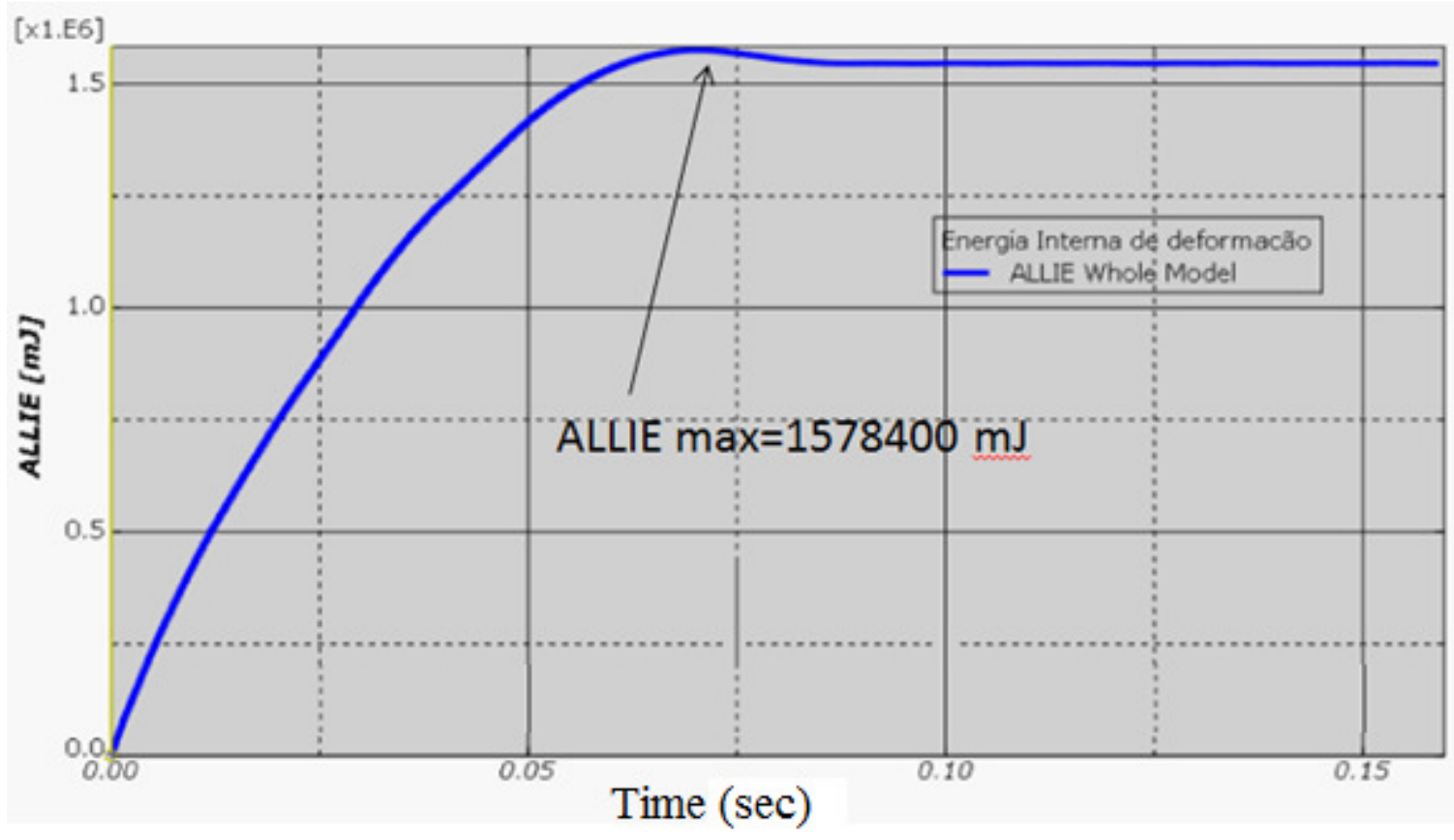


Figure 13 shows an Isight ${ }^{\circledR}$ output with the best optimization configuration obtained after several rounds by checking the various parameters provided.

Figure 13: Optimization flow results, in green the optimum value found.

\begin{tabular}{|c|c|c|c|}
\hline Espessura-input & Material-input & Offset & Crush_History_Max_ALLIE \\
\hline 1,8 & 1,0 & 4,0 & 1570500,0 \\
\hline 2,0 & 1,0 & 4,0 & 1570500,0 \\
\hline 1,8 & 2,0 & 4,0 & 1567400,0 \\
\hline 1,8 & 1,0 & 2,0 & 1578500,0 \\
\hline 2,6 & 2,0 & 2,0 & 1560600,0 \\
\hline 2,0 & 1,0 & 4,0 & 1570500,0 \\
\hline 2,2 & 1,0 & 4,0 & 1567100,0 \\
\hline 2,0 & 2,0 & 4,0 & 15669000 \\
\hline 2,0 & 1,0 & 2,0 & 1569300,0 \\
\hline
\end{tabular}

The optimal values obtained for model v1 are in table 2 , as well as the initial values imposed on model v0

Table. 2: Comparison between the initial model "v0" and the model "v1" optimized

\begin{tabular}{|cc|c|}
\hline Variable & Vo Model & V1 Model \\
\hline Thickness & $1.6 \mathrm{~mm}$ & $1.8 \mathrm{~mm}$ \\
\hline Offset & $0 \mathrm{~mm}$ & $2 \mathrm{~mm}$ \\
\hline Material (ID) & 1 & 1 \\
\hline Max penetration & $-52 \mathrm{~mm}$ & $-40 \mathrm{~mm}$ \\
\hline Crashbox height & $262 \mathrm{~mm}$ & $212 \mathrm{~mm}$ \\
\hline Mass & $1.5 \mathrm{Kg}$ & $1.47 \mathrm{Kg}$ \\
\hline
\end{tabular}


The optimized model showed a lower penetration, about $12 \mathrm{~mm}$ unless the initial model $\mathrm{v} 0$, as shown in figure 14

Figure 14: Crashbox penetration (Comparative)

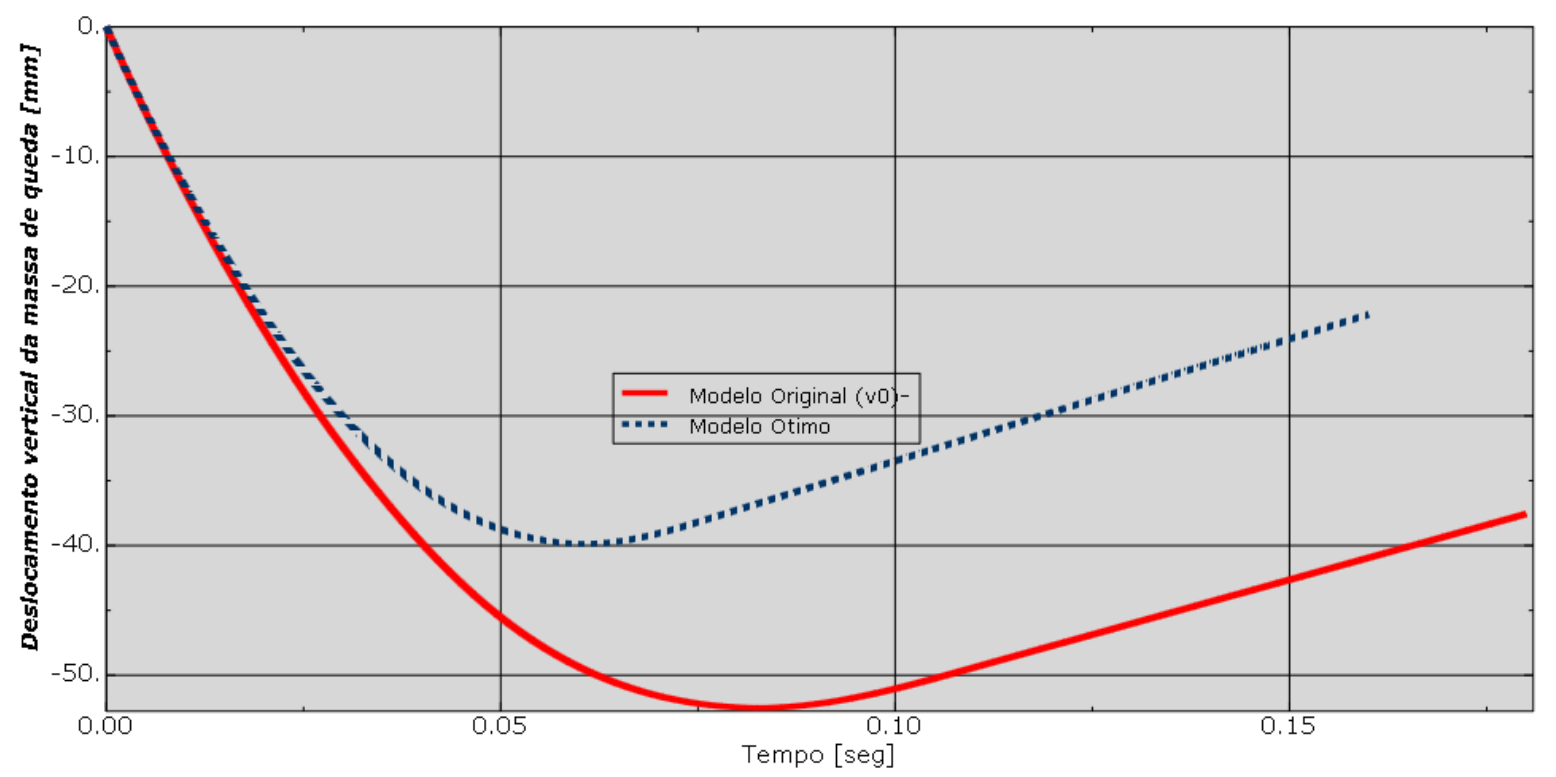

Even with a lower penetration, the dissipated energy was similar between the two models, as shown in Figure 15.

Figure 15: Internal energy (Comparative).

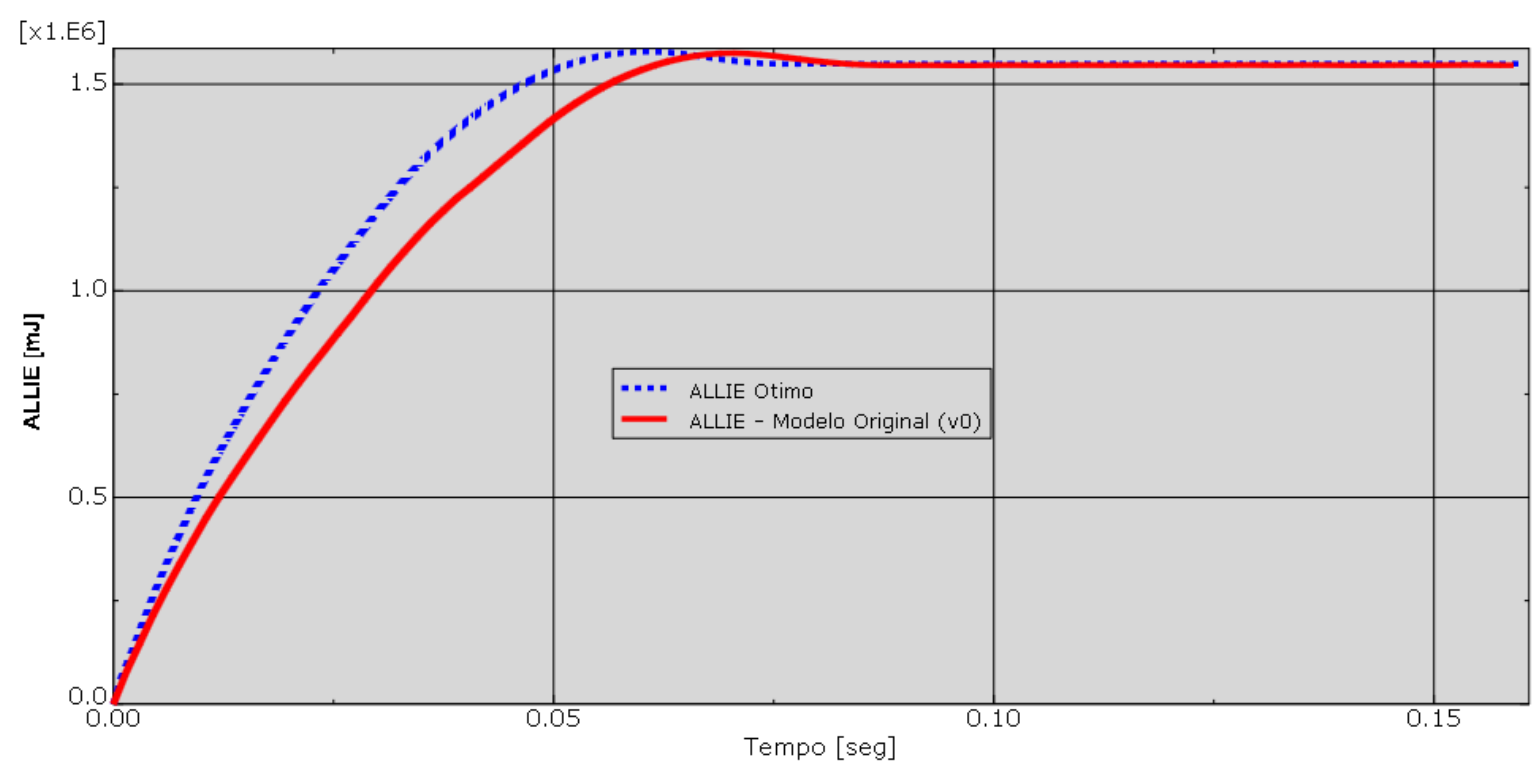




\section{CONCLUSION}

The use of computational tools to optimize a part was satisfactory, since with it one can modify and evaluate the influence of several variables response at the same time, a more complicated task to be carried out with only human resources and still has the advantage that these tasks performed by the numerical models can be executed in parallel to other activities, because once initialized, they do not require the human interventions.

In the proposed optimization, a lower part result was achieved with a better performance in the penetration response of the dropping mass with the same energy dissipation, that is, an optimized part.

Regarding weight, there was no significant change with input data imposed, although the optimized part was smaller, we had an increase in its thickness, which resulted in 3 grams reduction only, but with the result of the model v1 known for this variables scenario, one can choose to change variables or even imposed limits, as a greater freedom to increase cross-section, for example.

The present work used a crashbox as an example, but the methodology demonstrated can be applied to several components, not only in the automotive industry but in any other area, also being possible to optimize other parameters with other objectives.

\section{REFERENCES}

[1] Standard Regulation № 94 (ECE R94) - United Nations - Pages 15 and 19

[2] LIUYAN Jie; DING Lin, Influence of material properties on automobile energy absorbing components crashworthiness. The Open Mechanical Engineering Journal. 2014, 8, 113-116

[3] REYES, M. Langseth; HOPPERSTAD, O. S. An experimental and numerical study on the energy absorbing capability of aluminum extrusions under oblique loading

[4] MARZBANRAD, J.; KESHAVARZI, A. A numerical and experimental study on the crash behavior of the extruded aluminum crashbox with elastic support. Latin American Journal of Solids and Structures. 2014

[5] KALSHETTI, Ashutosh S.; PATIL, Sanjaysingh V. Energy absorption of varying thickness rectangular section crashbox for quasi-static axial loading. International Engineering Research Journal Page No 387-391 
[6] RAO, Singiresu S. Enginnering Optimization Theory and Practice, 2009.

[7] COUTINHO, Karilany Dantas. Método de otimização topológica em estruturas tridmensionais, 2006. Dissertação - Obtenção de título de mestre em engenharia mecânica, Universidade Federal do Rio Grande do Norte, Natal, 2006.

[8] TOBIAS, Miguel Bahia. Otimização topológica aplicada ao projeto de mecanismos flexíveis. 2005. Dissertação - Obtenção de título de mestre em engenharia, Universidade Federal de Santa Catarina, Florianópolis, 2005.

[9] SIGMUND, M.P Bendsoe, O. Topology Optimization Theory, Methods and Applications, 2003. 